\title{
Preparation and Characterization of Chitosan/Zinc Oxide Nanoparticles for Imparting Antimicrobial and UV Protection to Cotton Fabric
}

\author{
M. M. AbdElhady \\ Textile Research Division, National Research Centre, Dokki, Egypt \\ Correspondence should be addressed to M. M. AbdElhady, marwa_abdalhady@yahoo.com
}

Received 27 December 2011; Revised 30 January 2012; Accepted 6 February 2012

Academic Editor: R. J. Linhardt

Copyright () 2012 M. M. AbdElhady. This is an open access article distributed under the Creative Commons Attribution License, which permits unrestricted use, distribution, and reproduction in any medium, provided the original work is properly cited.

\begin{abstract}
Synthesis of chitosan/ZnO nanoparticles was performed using different concentrations of $\mathrm{ZnO}$ at different temperatures. Nanoparticles of $\mathrm{ZnO} /$ chitosan were prepared in rod form with average length $60 \mathrm{~nm}$ and average width $5-15 \mathrm{~nm}$. Thus, obtained nanoparticles of $\mathrm{ZnO} /$ chitosan were characterized using UV spectrophotometer, FTIR, TEM, X-ray, and SEM. Size and shape of chitosan/ZnO nanoparticles relied on conditions of their synthesis. Notably, chitosan/ZnO in rod form with average length of $60 \mathrm{~nm}$ and average width $5-15 \mathrm{~nm}$ could be achieved. Application of chitosan/ZnO nanoparticles to cotton fabric conferred on the latter antibacterial and UV protection properties. Cotton fabric was characterized using SEM, ultraviolet protection factor (UPF) rating, and antibacterial (gram-positive and gram-negative) characteristics. Finished cotton fabric exhibited good antibacterial properties against gram-positive and gram-negative bacteria. The UV testes indicated a significant improvement in UV protection of finished cotton fabric which is increasing by increasing the concentration of nanoparticles of $\mathrm{ZnO} /$ chitosan.
\end{abstract}

\section{Introduction}

Chitin, the second most abundant biopolymer, widely distributes in nature as the principal component of exoskeletons of crustaceans and insects as well as of cell walls of some bacteria and fungi. It is a glucose-based unbranched polysaccharide. It differs from cellulose at the C-2 carbon where an acetamido residue locates instead of a hydroxyl group. Chitosan is a partially deacetylated polymer of acetyl glucosamine obtained through alkaline deacetylation of chitin. It is a compound polymer of glucosamine and Nacetyl glucosamine. The term chitosan refers to a group of polymers varying in molecular weight upward to several million Daltons [1]. The structure of chitosan is very similar to that of cellulose; it consists of $\beta(1-4)$-linked D-glucosamine residue with the 2-hydroxyl group being substituted by an amino or acetylated amino group. The primary amine groups endow chitosan with many special properties, making it applicable in many areas and readily available for chemical reactions, for example, salt formation with acids. Chitosan is positively charged, making it able to adhere to the negatively charged surface. Chitosan is soluble in diverse acids and able to interact with polyanions to form complexes and gels. It holds antibacterial and antifungal properties. It is safe and nontoxic [2, 3]

With advent of nanotechnology, semiconductor nanoparticles have attracted much attention due to their novel optical, electrical, and mechanical properties. Among various semiconductor nanoparticles, nanosized zinc oxide $(\mathrm{ZnO})$ particles are the most frequently studied because of their interest in fundamental study and also their applied aspects such as in solar energy conversion, varistors, luminescence, photocatalysis, electrostatic dissipative coating, transparent UV protection films, and chemical sensors. Previously, $\mathrm{ZnO}$ nanoparticles have been prepared by techniques including the sol-gel method $[4,5]$, precipitation [6], hydrothermal synthesis [7], and spray pyrolysis [8].

Over recent years, hybrid materials based on chitosan have been developed, including conducting polymers, metal nanoparticles, and oxide agents, due to excellent properties of individual components and outstanding synergistic effects simultaneously [9]. Currently, the research on the combination of chitosan and metal oxide has focused 
on titanium dioxide, as titanium dioxide has excellent photocatalytic performance and is stable in acidic and alkaline solvents. Compared with titanium dioxide, zinc oxide has similar band-gap and antibacterial activity [9].

Sun protection creams and textiles are common choices to protect against UV radiation although UV radiation also weathers and degrades textiles. So many UV blocking agents are being developed to add or to improve the UV protection function of the textiles [10]. There are both organic and inorganic UV blockers. The organic blockers are also known as UV absorbers as they absorb the UV rays, whereas the inorganic blockers such as $\mathrm{TiO}_{2}$ and $\mathrm{ZnO}$ efficiently scatter both UVA and UVB, the main cause of skin cancer. Compared with organic UV absorbers, inorganic blockers are now preferred due to their properties such as nontoxicity and chemical stability under UV radiation [10-12].

Since chitosan has tremendous ability to form metal complexes with zinc metal $[13,14]$ because of its amine groups and hydroxyl groups currently, chitosan- $\mathrm{ZnO}$ complex attracted great interests for its potential use as UV protector and medicament. This work is focused on (i) preparation and characterization of chitosan/zinc oxide nanorods complex using precipitation method and (ii) application of chitosan/ZnO nanoparticles on cotton fabric to impart antibacterial properties and UV protection.

\section{Experimental}

2.1. Materials. Mill-bleached $100 \%$ cotton fabric was kindly supplied by Misr Company for spinning and weaving Mehalla El Kobra, Egypt. Chitosan is poly [ $\beta$-2-amino-2deoxy-(1-4)-D glucopyranose] with a molecular weight of $60,000 \mathrm{Da}$, and a deacetylation degree of $85 \%$ was supplied by Fluka. Zinc oxide $(\mathrm{ZnO})$, sodium hydroxide $(\mathrm{NaOH})$, and acetic acid were of laboratory grade chemicals.

2.2. Preparation of Chitosan/Zinc Oxide Nanoparticles. The accurate weight of $\mathrm{ZnO}$ powder $(0.1-1 \mathrm{gm})$ was dissolved in $100 \mathrm{~mL}$ of $1 \%$ acetic acid where it changed to zinc cations. To this solution $1 \mathrm{gm}$ of chitosan was added. The mixture was sonicated for $30 \mathrm{~min}$. After magnetic stirring, $1 \mathrm{M} \mathrm{NaOH}$ drop by drop was added until the solution attained $\mathrm{pH} 10$. The solution was heated in water bath at $\left(40-80^{\circ} \mathrm{C}\right)$ for about $3 \mathrm{hr}$. It was then filtered and washed with distilled water several times then dried in an oven at $50^{\circ} \mathrm{C}$ for $1 \mathrm{hr}$.

2.3. Application Chitosan/Zinc Oxide Nanoparticles to Cotton Fabric. $0.5-4$ wt \% Chitosan/ZnO nanoparticles powder was suspended in water and was sonicated for $10 \mathrm{~min}$. In these suspensions bleached cotton fabric samples were padded in two dip and nip and then squeezed to a wet pick-up of $100 \%$. The samples were then dried at $100^{\circ} \mathrm{C}$ for $10 \mathrm{~min}$ and cured at $170^{\circ} \mathrm{C}$ for $5 \mathrm{~min}$. The so treated cotton fabrics were washed with distilled water and finally dried at ambient conditions.

\subsection{Characterization}

2.4.1. UV-Vis Spectrum. UV-vis spectrum was recorded on Perkin Elmer Lambda 3B UV-vis spectrometer. Ultraviolet protection factor (UPF) was measured using UV Shimadzu 3101 PC spectrophotometer.

2.4.2. FTIR Spectroscopy. FTIR spectroscopy was measured using FT-IR, model: Nexus 670 (Nicollet-Madison-WIUSA). The samples were mixed uniformly with potassium bromide at $1: 5$ (sample: $\mathrm{KBr}$ ) ratio, respectively. The $\mathrm{KBr}$ discs were prepared by compressing the powders (mixture of sample and $\mathrm{KBr}$ ) at pressure of 5 tons for $5 \mathrm{~min}$ in a hydraulic press. The discs were scanned in the range of $400-4000 \mathrm{~cm}^{-1}$ to obtain FT-IR spectra.

2.4.3. Scanning Electron Microscope (SEM). Fabric samples under investigation were examined by a JEOL-840X scanning electron microscope, from Japan, magnification range 3510,000 , resolution $200 \AA$, acceleration voltage $19 \mathrm{kV}$. All the samples were coated with gold before SEM testing.

2.4.4. Transmission Electron Microscope (TEM). Transmission electron microscope (TEM) observation was performed on a JEOL JEM-1230 electron microscope at accelerating voltage of $120 \mathrm{kV}$. Specimens for TEM measurements were prepared by depositing a drop of colloid solution on a 400 mesh copper grid coated by an amorphous carbon film and evaporating the solvent in air at room temperature.

2.4.5. X-Ray Diffraction (XRD). XRD patterns recorded on a Philips PW 3050/10 model. The samples were recorded on a Philips X-Pert MMP diffractometer. The diffractometer was controlled and operated by a PC computer with the programs P Rofit and used a MoK (source with wavelength $0.70930 \AA$, operating with Mo-tube radiation at $50 \mathrm{kV}$ and $40 \mathrm{~mA}$.

2.4.6. Antibacterial Activity. Antibacterial activity towards Staphylococcus aureus (S. aureus, gram-positive bacteria) and Escherichia coli (E. coli, gram-negative bacteria) was evaluated using Agar Plate Method (AATCC Test Method 147-1988).

\section{Results and Discussion}

3.1. Preparation of Chitosan/ZnO Nanoparticles (Effect of Process Parameters). The prepared Chitosan/ZnO nanoparticles at $40-80^{\circ} \mathrm{C}$ in powder form were suspended in water and sonicated for $10 \mathrm{~min}$ then characterized by UV-vis absorbance spectra.

3.1.1. Effect of Concentration of Zinc Oxide. Figure 1 shows UV-vis absorbance spectra of chitosan and prepared chitosan/ZnO nanoparticles at $60^{\circ} \mathrm{C}$. Obviously, (Figure 1, curve a), chitosan exhibits characteristic peak at $226 \mathrm{~nm}$. After incorporation of different concentrations of $\mathrm{ZnO}$ in chitosan, this peak undergoes a characteristic peak at range $360-348 \mathrm{~nm}$ is which observed.

In detail, at a concentration of $0.1 \% \mathrm{ZnO}$ (Figure 1, curve b), there is an absorption peak observed at $360 \mathrm{~nm}$, 


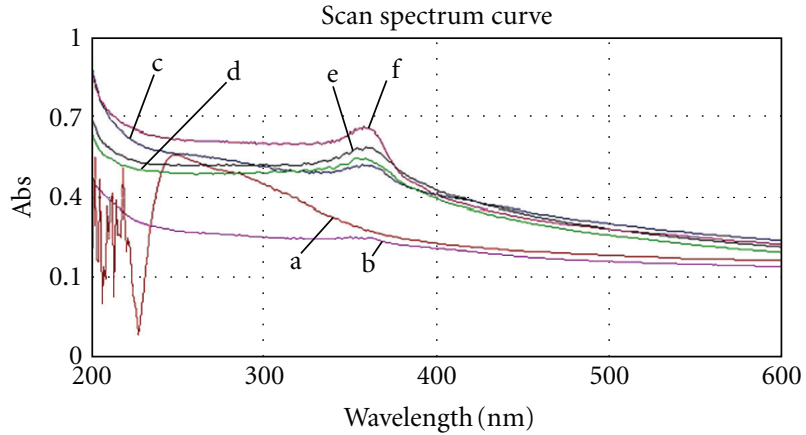

Figure 1: UV-vis absorbance spectra of chitosan and chitosan/ZnO nanoparticles at different concentrations. (a) chitosan, (b) chitosan/ZnO (0.1\%), (c) chitosan/ZnO (0.25\%), (d) chitosan/ZnO (0.5\%), (e) chitosan/ZnO (0.75\%) and (f) chitosan/ZnO (1\%).

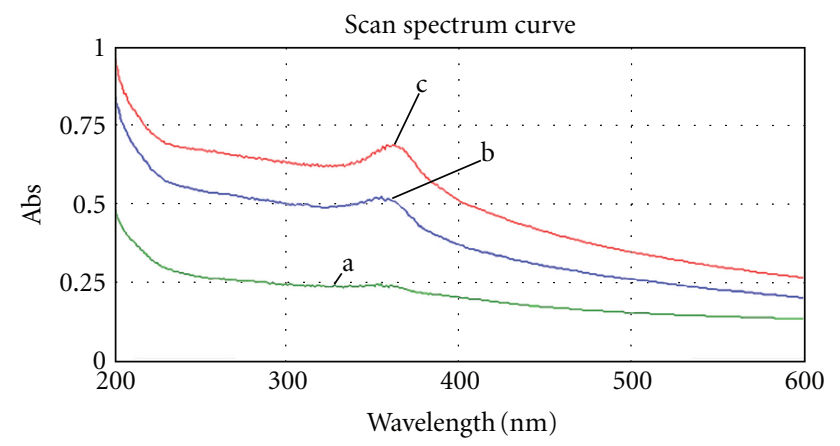

FIGURE 2: UV-vis absorbance spectra of chitosan and chitosan/ZnO $(0.75 \%)$ nanoparticles at different temperatures (a) at $40^{\circ} \mathrm{C}$, (b) at $60^{\circ} \mathrm{C}$, and (c) at $80^{\circ} \mathrm{C}$.

indicating the formation of nanoparticles of chitosan/ZnO in larger size. By increasing the concentration of $\mathrm{ZnO}$ to 0.25 , 0.5 , and $0.75 \%$ (Figure 1 , curves c, d, and e), the absorption peaks are shifted to 356,350 , and $348 \mathrm{~nm}$, respectively. Increasing the concentration of $\mathrm{ZnO}$ further to $1 \%$ (Figure 1, curve f), the absorption peak changes to about $350 \mathrm{~nm}$. This could be attributed to formation of smaller nanoparticles of chitosan/ $\mathrm{ZnO}$ complex. So that higher concentrations of $\mathrm{ZnO}$ are recommended.

3.1.2. Effect of Temperature. Figure 2 shows UV-vis spectra of different chitosan/ZnO nanoparticles samples prepared at $0.75 \%$ wt of $\mathrm{ZnO}$ and different temperatures. It is seen that, at temperature $40^{\circ} \mathrm{C}$ (Figure 2, spectrum a), the absorption peak is observed at $356 \mathrm{~nm}$. Increasing the preparation temperature to $60^{\circ} \mathrm{C}$ and $80^{\circ} \mathrm{C}$ results in shifting towards lower absorption bands of 348 and $353 \mathrm{~nm}$ (Figure 2, spectra $\mathrm{b}$ and $\mathrm{c}$ ). This could be attributed to complete conversion of chitosan- $\mathrm{Zn}(\mathrm{OH})_{2}$ complexes to $\mathrm{ZnO}$ nanoparticles under the influence of higher temperature.

Based on the above results, it is clear that all the concentrations of $\mathrm{ZnO}$ used in the synthesis of chitosan/ $\mathrm{ZnO}$ produce complexes which assume nanocrystalline form, in contrast with the macrocrystalline form with an absorption band at $372 \mathrm{~nm}$ when $\mathrm{ZnO}$ alone was used [9].

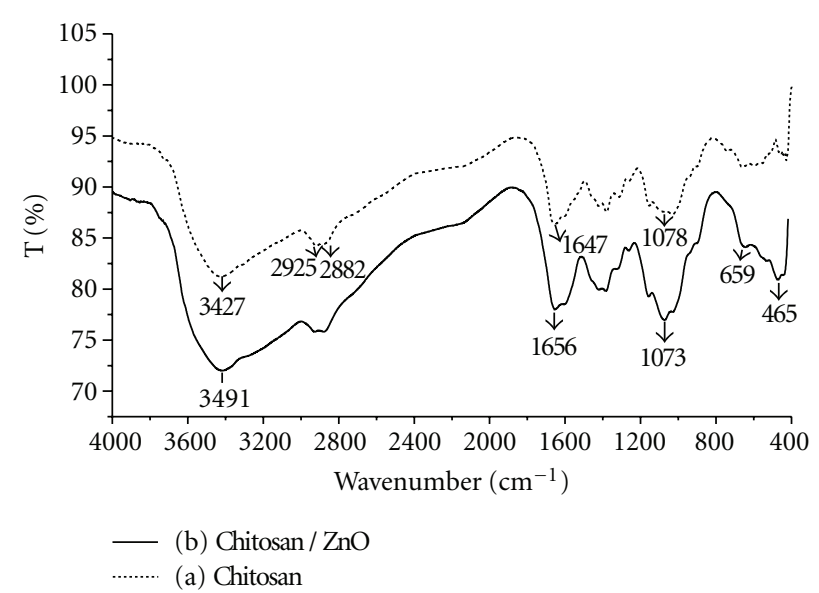

FIGURE 3: FTIR of chitosan (a) and chitosan/ZnO nanaoparticles (b).

The optimum concentration of $\mathrm{ZnO}$ for formation of chitosan/ZnO nanoparticles is $0.75 \%$, and the optimum temperature is $60^{\circ} \mathrm{C}$; under this condition an absorption peak at $348 \mathrm{~nm}$ is and shifted by $22 \mathrm{~nm}$ than macrocrystalline $\mathrm{ZnO}$. This indicates that $\mathrm{ZnO}$ within chitosan complex is in the nanoscale and in full agreement with IR and X-ray analysis as will be shown latter.

3.2. Mechanism of Formation of Chitosan/ZnO Nanoparticles. When chitosan and zinc oxide are dissolved in diluted acetic acid; thereby; adjusting the acidity of solution, $\mathrm{Zn}^{2+}$ ions were formed. At $\mathrm{pH}=(6$ to 9$)$ the unstable compound $\mathrm{Zn}[(\mathrm{OH})]_{2}$ was formed, according to the following equation:

$$
\mathrm{Zn}^{2+}+2 \mathrm{OH} \rightleftharpoons \mathrm{Zn}(\mathrm{OH})_{2}
$$

Since chitosan $\mathrm{NH}_{2}$ and $\mathrm{OH}$ groups can form co-ordination bond with metal ions [15], by increasing $\mathrm{pH}$ of the solution to $\mathrm{pH}=10$ dropwise addition of $\mathrm{NaOH}$, the stable complex of chitosan/ZnO nanoparticles is formed.

3.3. IR Analysis. (Figure 3, curves a and b) depicts the FTIR of chitosan and chitosan/ZnO nanaoparticles. For chitosan (Figure 3(a)) shows absorption peak at $3427 \mathrm{~cm}^{-1}$. This attributed to the combined peaks of the $\mathrm{NH}_{2}$ and $\mathrm{OH}$ group stretching vibration [16]. Compared with chitosan, (curve 3-b), the broader and stronger peak moved noticeably to lower wave number at $3419 \mathrm{~cm}^{-1}$ which indicated the strong interaction between these groups and $\mathrm{ZnO}$ [17]. The absorption peaks at $2925,2882 \mathrm{~cm}^{-1}$ are attributed to asymmetric stretching of $\mathrm{CH}_{3}$ and $\mathrm{CH}_{2}$ of chitosan polymer [16]. While the absorption peaks at 1647 and $1078 \mathrm{~cm}^{-1}$ are ascribed to bending vibration of $-\mathrm{NH}_{2}$ group and $\mathrm{C}-$ $\mathrm{O}$ stretching group, compared with chitosan, there are new absorption peaks at $659 \mathrm{~cm}^{-1}$ and $465 \mathrm{~cm}^{-1}$ which are due to the attachment of amide group and stretching mode of $\mathrm{ZnO}$ [18]. In addition to these results, the characteristic peaks of (Figure 3(b)) are shifted to lower wavenumber, the wide peak at $3427 \mathrm{~cm}^{-1}$, corresponding to the stretching vibration of hydroxyl, amino and amide groups, moved noticeably 


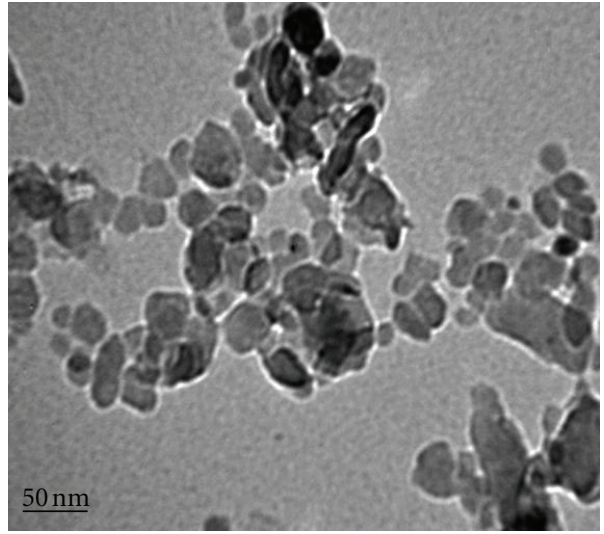

(a) Chitosan/ZnO nanoparticals $(0.5 \%)$ at $60^{\circ} \mathrm{C}$

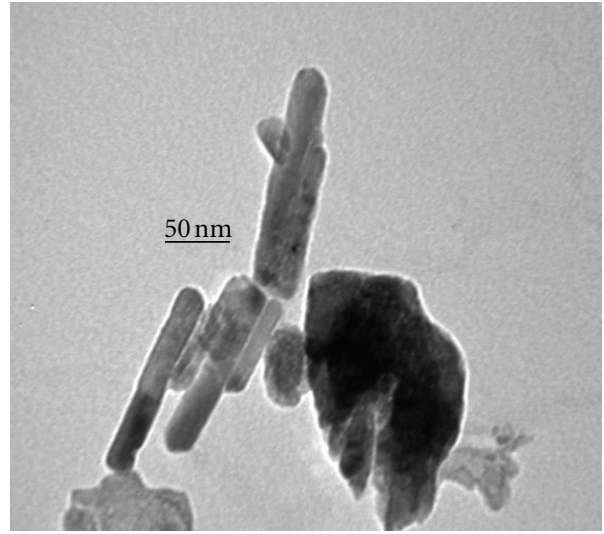

(b) Chitosan/ZnO nanoparticals $(0.75 \%) 60^{\circ} \mathrm{C}$

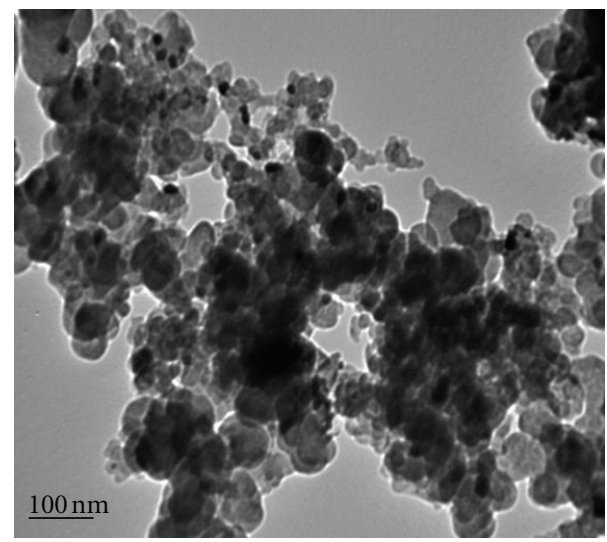

(c) Chitosan/ZnO nanoparticals $(0.75 \%) 80^{\circ} \mathrm{C}$

FiguRE 4: TEM photographs of chitosan/ZnO nanoparticles.

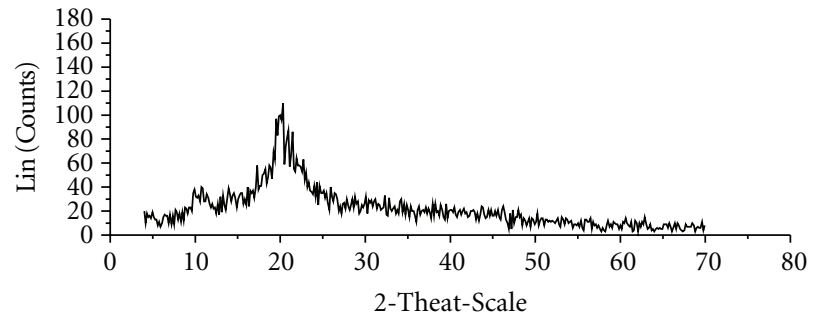

(a)

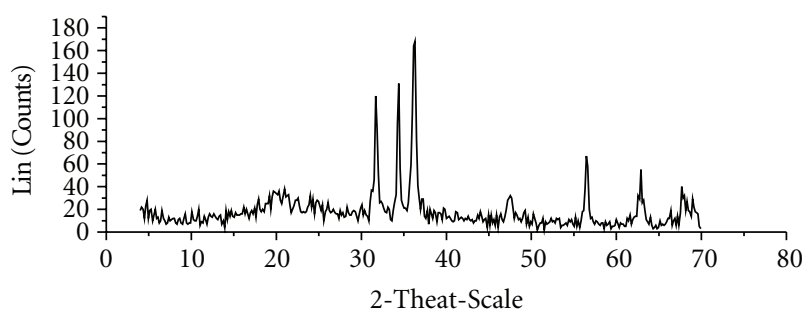

(b)

FIGURE 5: X-ray diffraction patterns of chitosan (a) and chitosan/ZnO nanoparticles (b).

to lower wavenumbers $3419 \mathrm{~cm}^{-1}$, and became broader and stronger, which indicated the strong interaction between these groups and $\mathrm{ZnO}$, compared with Figure 3(a), a point which could be explained in terms of strong attachment of $\mathrm{ZnO}$ to the amide groups of chitosan molecules.

3.4. TEM Analysis. Figure 4 represents TEM photograph of chitosan/ZnO nanoparticles. It is evident that at concentration $0.5 \%$, nanospheres $\mathrm{ZnO}$ are formed with average sizes $10-20 \mathrm{~nm}$. While increasing the concentration of $\mathrm{ZnO}$ up to $0.75 \%$, the average length of $\mathrm{ZnO}$ nanorods increases to $60 \mathrm{~nm}$ keeping the average width at $5-15 \mathrm{~nm}$. This could be interpreted in terms of lower concentration of $\mathrm{ZnO}(0.5 \%$ at $60^{\circ} \mathrm{C}$ ) which leads to incomplete growth of nanoparticles of chitosan/ZnO complex. On the other hand, $\mathrm{ZnO}$ concentrations as high as $0.75 \%$ give complete growth of nanorods. It is also evident that increasing the temperature from $60^{\circ} \mathrm{C}$ to $80^{\circ} \mathrm{C}$ is accompanied by breakingdown of nanorods to nanospheres (Figure 4(c)) with higher agglomeration of smaller size nanoparticles having 5-10 nm.

3.5. X-Ray Analysis. Figure 5 shows the $\mathrm{X}$-ray diffraction patterns of chitosan and chitosan/ZnO nanoparticles. The typical peaks of chitosan (Figure 5(a)) appeared at $10.67^{\circ}$ and $19.99^{\circ}$ [9], while these peaks become weak in the XRD pattern of chitosan/ZnO nanoparticals (Figure 5(b)). Other 


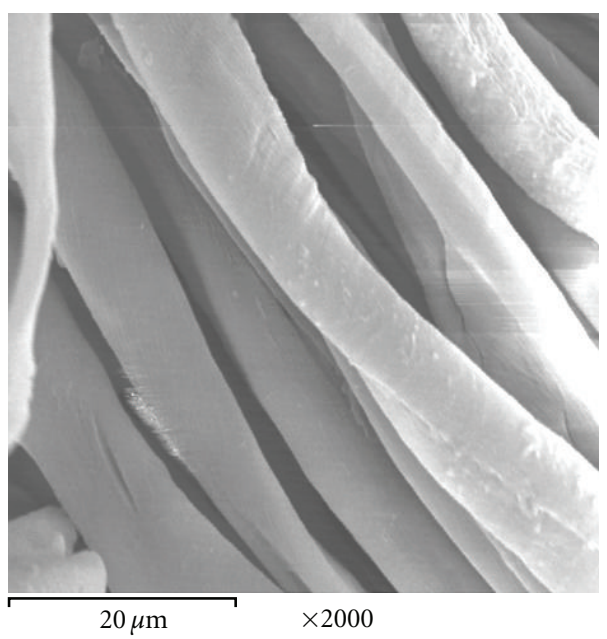

(a) Untreated cotton fabric

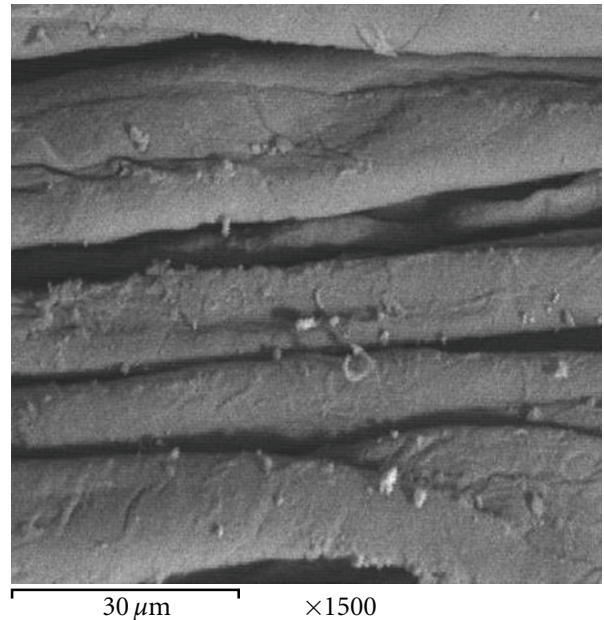

(b) Cotton fabric treated with chitosan/zinc oxide nanoparticles

FiguRE 6: SEM of cotton fabric treated with chitosan/ZnO nanoparticles.

TABLE 1: The antibacterial activity and UPF rating of bleached cotton fabric treated by chitosan/ZnO nanoparticles.

\begin{tabular}{|c|c|c|c|}
\hline \multirow{2}{*}{ Concentration of chitosan/ZnO nanoparticles (\%) } & \multicolumn{2}{|c|}{ Inhibition zone (mm) } & \multirow{2}{*}{ UPF rating } \\
\hline & S. aureus & E. coli & \\
\hline $0.0^{\mathrm{a}}$ & - & - & 1.5 \\
\hline 0.5 & 5 & 7 & 3.5 \\
\hline 1 & 9 & 10 & 4.8 \\
\hline 2 & 11 & 12 & 6.0 \\
\hline 4 & 11 & 13 & 8.3 \\
\hline
\end{tabular}

${ }^{a}$ Represents the untreated bleached cotton fabric.

Condition used: cotton fabric treated by chitosan/ $\mathrm{ZnO}$ nanoparticles $(0.75 \%)$ at pickup $100 \%$, dried at $100^{\circ} \mathrm{C}$ for $10 \mathrm{~min}$, and then cured at $170^{\circ} \mathrm{C}$ for $5 \mathrm{~min}$.

diffraction peaks in Figure 5(b) are sharper and stronger at $31.7^{\circ}, 34.36^{\circ}, 36.2^{\circ}, 56.59^{\circ}, 62.7^{\circ}$, and $67.90^{\circ}$ and were assigned to the $\left(\begin{array}{lll}1 & 0 & 0\end{array}\right),\left(\begin{array}{lll}0 & 0 & 2\end{array}\right),\left(\begin{array}{lll}1 & 0 & 1\end{array}\right),\left(\begin{array}{lll}1 & 1 & 0\end{array}\right),\left(\begin{array}{ll}1 & 0\end{array}\right.$ 3), and ( $\left.\begin{array}{lll}1 & 1 & 2\end{array}\right)$ planes of hexagonal zinc oxide can be indexed to the wurtzite $\mathrm{ZnO}$ with high crystallinity. All the diffraction peaks are in good agreement with those of hexagonal wurtzite structure of $\mathrm{ZnO}$ (JCPDS card 36-1451) [16]. This, indeed, revealed that it is successful formation of nanosized chitosan/ZnO complex [18].

3.6. Scan Electron Microscope. The surface characteristics of untreated and chitosan/ZnO nanoparticals treated cotton fabric were examined by scanning electron microscopy, and the images obtained are shown in Figure 6. In Figure 6(a), the untreated cotton fabric seems to be a smooth fibers. While with cotton fabric treated with chitosan/ $\mathrm{ZnO}$ nanoparticles Figure 6(b), nanoparticles are dispersed on the surface of the fiber.

3.7. Antibacterial Activity. Different cotton swatches were treated with different concentrations of chitosan/ZnO nanoparticles. These swatches were monitored for antibacterial activities. Results obtained are set out in Table 1. It is seen that the circular inhibition zone increases with increasing the concentrations of chitosan/ $\mathrm{ZnO}$ nanoparticles in the range studied. It is also observed (Table 1) that the inhibition zone for $E$. coli is greater than the inhibition zone for $S$. aureus. This could be associated with differences in cell wall structure. At any event, however, the antibacterial activity could be attributed to the antibacterial effect of chitosan [19] and photocatalysis of $\mathrm{ZnO}$.

Photocatalysis mechanism was as follows: when $\mathrm{ZnO}$ nanoparticles $(E g=3.37 \mathrm{eV})$ were under light irradiation, the electron transition from the valence band to the conduction band resulted in the electron-hole pair in which electron $\left(\mathrm{e}^{-}\right)$was reductive, and hole $\left(\mathrm{h}^{+}\right)$was oxidative. The hole $\left(\mathrm{h}^{+}\right)$reacted with $\mathrm{OH}^{-}$on the surface of $\mathrm{ZnO}$ nanoparticles, generating hydroxyl radicals $\left(\mathrm{OH}^{-}\right)$, superoxide anion $\left(\mathrm{O}_{2}{ }^{-}\right)$, and perhydroxyl radicals $\left(\mathrm{HO}_{2}{ }^{-}\right)$. These highly active free radicals and actual lethal agent hydrogen peroxide $\left(\mathrm{H}_{2} \mathrm{O}_{2}\right)$, produced from $\mathrm{OH}^{-}$and $\mathrm{O}_{2}{ }^{-}$, could damage the cells of bacteria, leading to decomposition, complete destruction of its internal structure, eventually, to achieve germicidal and antibacterial effects [20].

3.8. UV Protection. Table 1 shows also UV protection of bleached cotton fabric treated by chitosan/ZnO nanoparticles. It is clearly seen from that ultraviolet protection 
factor (UPF) of the treated samples is higher than that of untreated cotton fabric. Also UPF rating increases by increasing the concentration of chitosan/ $\mathrm{ZnO}$ nanoparticles from $0.5 \%$ to $4 \%$. This reflects the capacity of UV absorption of $\mathrm{ZnO} /$ nanoparticles on the surface of the cotton fabric [21].

\section{Conclusion}

Synthesis and characterization of chitosan/ZnO nanaoparticles were investigated. Chitosan/ZnO nanoparticles were characterized using UV-vis spectrophotometer at different concentrations of $\mathrm{ZnO}$ and different temperature. The optimum concentration of $\mathrm{ZnO}$ for formation of nanoparticles is $0.75 \%$, and the optimum temperature is $60^{\circ} \mathrm{C}$. The obtained nanoparticles were investigated using FTIR, TEM, and X-ray analysis. Based on TEM results, it is shown nanoparticles in rod form with average length $60 \mathrm{~nm}$ and average width 515. Coating of cotton fabric by thus obtained chitosan/ZnO nanoparticles enhances the UV absorbing activity of treated fabric. Also the treated fabric has significant improvement at antibacterial properties. From the above results, this innovation is important because it may allow its practical use for industrial applications.

\section{References}

[1] S. Sevda and S. J. McClure, "Potential applications of chitosan in veterinary medicine," Advanced Drug Delivery Reviews, vol. 56, no. 10, pp. 1467-1480, 2004.

[2] S. A. Agnihotri, N. N. Mallikarjuna, and T. M. Aminabhavi, "Recent advances on chitosan-based micro- and nanoparticles in drug delivery," Journal of Controlled Release, vol. 100, no. 1, pp. 5-28, 2004.

[3] S. K. Kim and N. Rajapakse, "Enzymatic production and biological activities of chitosan oligosaccharides (COS): a review," Carbohydrate Polymers, vol. 62, no. 4, pp. 357-368, 2005.

[4] N. B. Hubbard, M. L. Culpepper, and L. L. Howell, "Actuators for micropositioners and nanopositioners," Applied Mechanics Reviews, vol. 59, no. 1-6, pp. 324-334, 2006.

[5] H. J. Lee, S. Y. Yeo, and S. H. Jeong, "Antibacterial effect of nanosized silver colloidal solution on textile fabrics," Journal of Materials Science, vol. 38, no. 10, pp. 2199-2204, 2003.

[6] L. Wang and M. Muhammed, "Synthesis of zinc oxide nanoparticles with controlled morphology," Journal of Materials Chemistry, vol. 9, no. 11, pp. 2871-2878, 1999.

[7] H. Y. Xu, H. Wang, Y. C. Zhang et al., "Hydrothermal synthesis of zinc oxide powders with controllable morphology," Ceramics International, vol. 30, no. 1, pp. 93-97, 2004.

[8] T. Tani, L. Mdler, and S. E. Pratsinis, "Homogeneous $\mathrm{ZnO}$ nanoparticles by flame spray pyrolysis," Journal of Nanoparticle Research, vol. 4, no. 4, pp. 337-343, 2002.

[9] L. H. Li, J. C. Deng, H. R. Deng, Z. L. Liu, and L. Xin, "Synthesis and characterization of chitosan/ZnO nanoparticle composite membranes," Carbohydrate Research, vol. 345, no. 8, pp. 994-998, 2010.

[10] G. Reinert, F. Fuso, R. Hilfiker, and E. Schmidt, "UVprotecting properties of textile fabrics and their improvement," Textile Chemist and Colorist, vol. 29, no. 12, pp. 36-43, 1997.
[11] H. Yang, S. Zhu, and N. Pan, "Studying the mechanisms of titanium dioxide as ultraviolet-blocking additive for films and fabrics by an improved scheme," Journal of Applied Polymer Science, vol. 92, no. 5, pp. 3201-3210, 2004.

[12] T. Ohno, K. Sarukawa, K. Tokieda, and M. Matsumura, "Morphology of $\mathrm{TiO}_{2}$ photocatalyst (Degussa, P-25) consisting of anatase and rutile crystalline phases," Journal of Catalysis, vol. 203, no. 1, pp. 82-86, 2001.

[13] R. A. A. Muzzarelli and L. Sipos, "Chitosan for the collection from seawater of naturally occurring zinc, cadmium, lead and copper," Talanta, vol. 18, no. 9, pp. 853-858, 1971.

[14] R. A. A. Muzzarelli and O. Tubertini, "Chitin and chitosan as chromatographic supports and adsorbents for collection of metal ions from organic and aqueous solutions and sea-water," Talanta, vol. 16, no. 12, pp. 1571-1577, 1969.

[15] A. Higazy, M. Hashem, A. ElShafei, N. Shaker, and M. M. Abdel Hady, "Development of antimicrobial jute packaging using chitosan and chitosan-metal complex," Carbohydrate Polymers, vol. 79, no. 4, pp. 867-874, 2010.

[16] M. Guo, P. Diao, and S. Cai, "Hydrothermal growth of wellaligned $\mathrm{ZnO}$ nanorod arrays: dependence of morphology and alignment ordering upon preparing conditions," Journal of Solid State Chemistry, vol. 178, no. 6, pp. 1864-1873, 2005.

[17] R. Salehi, M. Arami, N. M. Mahmoodi, H. Bahrami, and S. Khorramfar, "Novel biocompatible composite (Chitosanzinc oxide nanoparticle): preparation, characterization and dye adsorption properties," Colloids and Surfaces B, vol. 80, no. 1, pp. 86-93, 2010.

[18] P. Bhadra, M. K. Mitra, G. C. Das, R. Dey, and S. Mukherjee, "Interaction of chitosan capped $\mathrm{ZnO}$ nanorods with Escherichia coli," Materials Science and Engineering C, vol. 31, no. 5, pp. 929-937, 2011.

[19] I. M. Helander, E.-L. Nurmiaho-Lassila, R. Ahvenainen, J. Rhoades, and S. Roller, "Chitosan disrupts the barrier properties of the outer membrane of Gram-negative bacteria," International Journal of Food Microbiology, vol. 71, no. 2-3, pp. 235-244, 2001.

[20] B. Halliwell and J. M. C. Gutteridge, "Oxygen toxicity, oxygen radicals, transition metals and disease," Biochemical Journal, vol. 219, no. 1, pp. 1-14, 1984.

[21] S. Kathirvelu, D. Souzaa, and B. Dhurai, "UV protection finishing of textiles using $\mathrm{ZnO}$ nanoparticals," Indian Journal of Fiber and Textile Research, vol. 34, no. 3, pp. 267-273, 2009. 


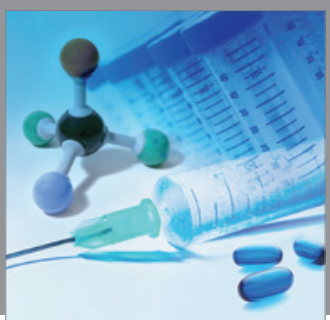

International Journal of

Medicinal Chemistry

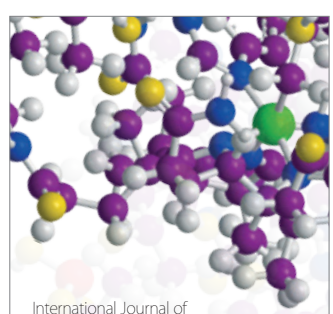

Carbohydrate Chemistry

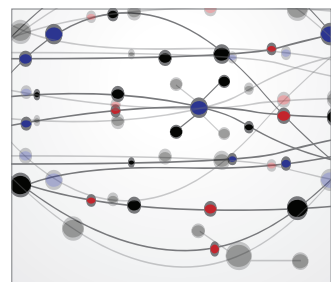

The Scientific World Journal
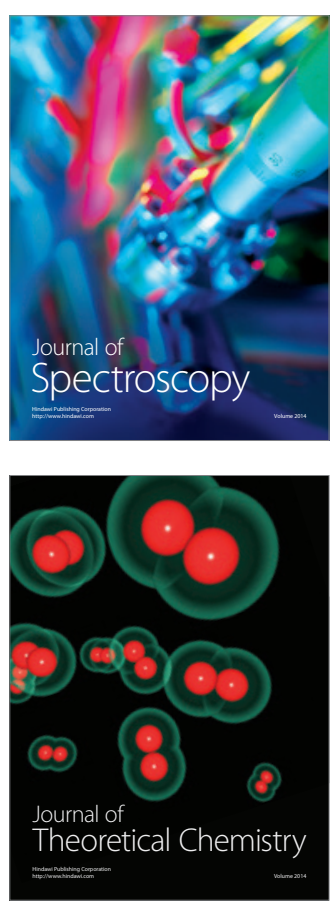
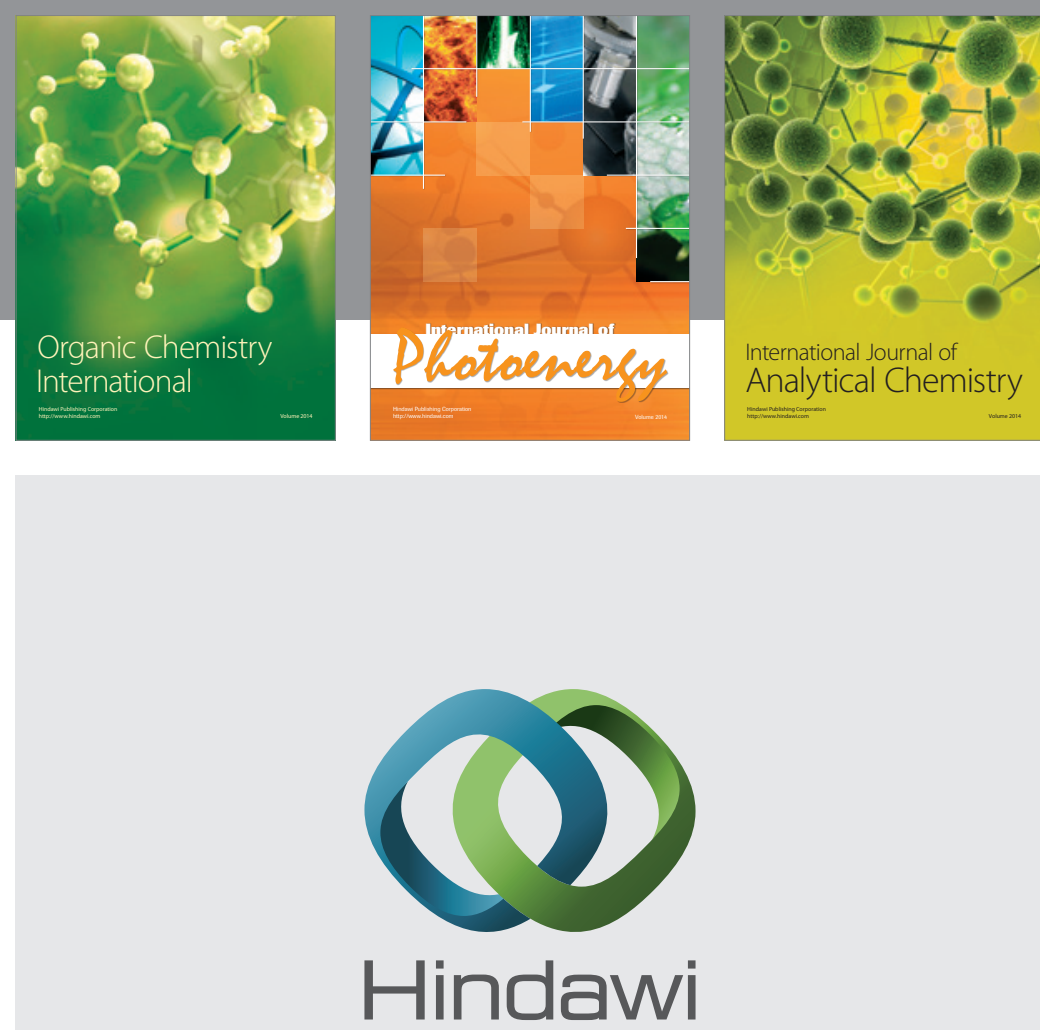

Submit your manuscripts at

http://www.hindawi.com
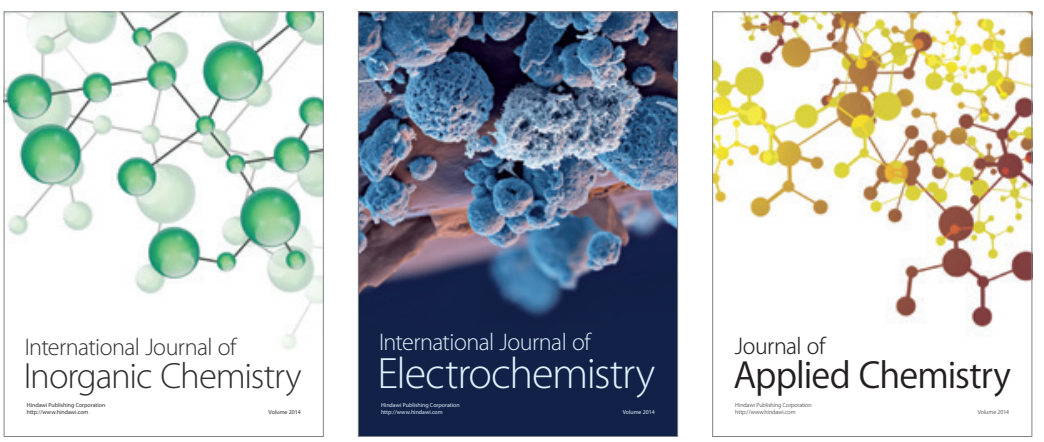

Journal of

Applied Chemistry
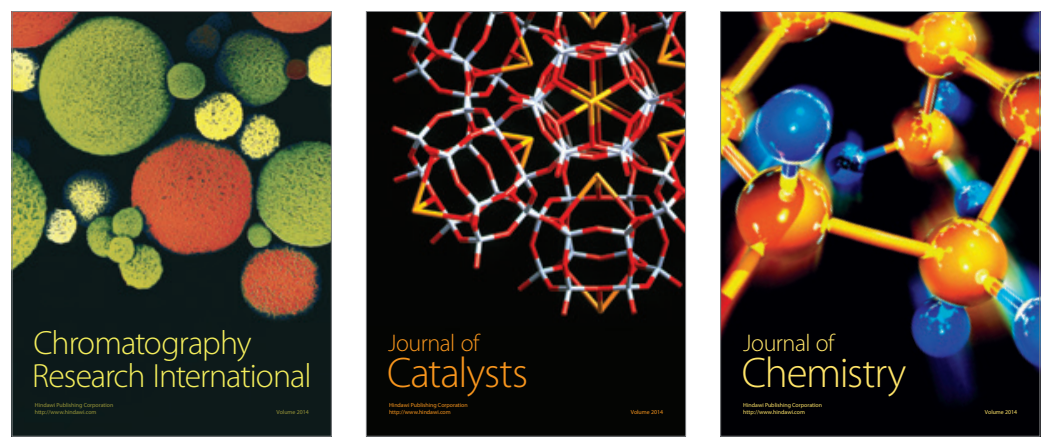
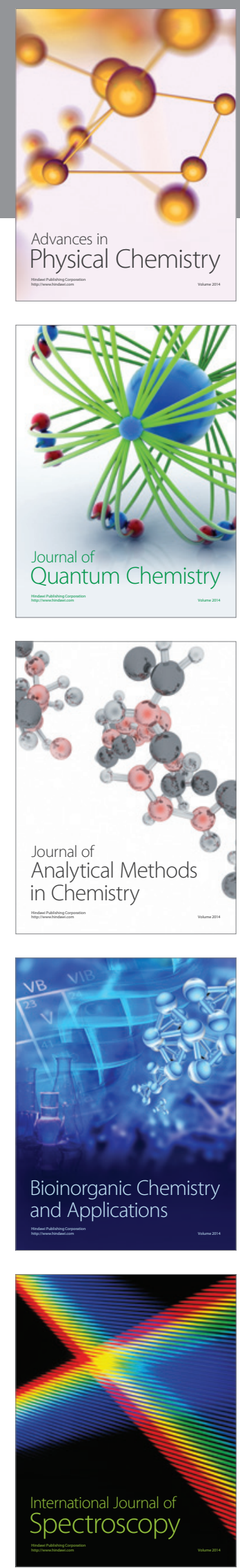